\title{
Personality Differences in Perception: The Role of Incongruity Intolerance and Mental Schemata on Aesthetic Preferences
}

\author{
Valeria Biasi' ${ }^{1}$ Paolo Bonaiuto², Nazarena Patrizi' ${ }^{1}$ James M. Levin ${ }^{3}$ \\ ${ }^{1}$ Department of Education, "Roma Tre" University, Rome, Italy \\ ${ }^{2}$ Faculty of Medicine and Psychology, "Sapienza" Universityof Rome, Rome, Italy \\ ${ }^{3}$ John Jay College, City University of New York, New York, USA \\ Email: valeria.biasi@romascuola.net, paolo.bonaiuto@uniroma1.it, nazarena.patrizi@uniroma3.it, \\ jameslevin@msn.com
}

Received 24 August 2015; accepted 19 October 2015; published 22 October 2015

Copyright (C) 2015 by authors and Scientific Research Publishing Inc.

This work is licensed under the Creative Commons Attribution International License (CC BY).

http://creativecommons.org/licenses/by/4.0/

(c) $\underset{\mathrm{EY}}{\mathrm{B}}$ Open Access

\section{Abstract}

The influence of incongruity intolerance levels on people's aesthetic preference of three categories of classic and modern artistic paintings was examined. The study uses pictures that trigger in the observer the amodal completion, which involves the application and confirmation of already consolidated mental schemata, or the perceptual contradiction, which highlights their non-confirmation, generating incongruity experience. As in a first preliminary study conducted by Bonaiuto, Biasi, Giannini, \& Chiodetti (2001) with advertising images, incongruity intolerance levels were assessed with the Building Inclination Test (BIT). Also in this new study, we apply the BIT tool in order to select sixty young adults, divided into three subgroups: 20 very incongruity intolerant participants, 20 very incongruity tolerant ones, and 20 intermediate participants, both genders equally subdivided. Moreover, we selected eighteen colour laser reproductions of classical and modern artistic paintings on A4 paper sheets: six show the predominant completion phenomena, other six are based on clear incongruous situations and the last six show completion phenomena mixed with incongruity. Each participant individually evaluated each illustration on aesthetic and physiognomic aspects, using 11-point scales. Double-blind experimental conditions were assured. The results show that very incongruity intolerant participants highly aesthetically appreciate the completion pictures, but they do not like the incongruent pictures. Differently the very incongruity tolerant participants are able to appreciate all three types of images presented, and attribute positive aesthetic scores also to the incongruent and thus conflictual pictures. The third group of participants is characterized by intermediate level of incongruity intolerance and obtain intermediate scores. Collected data confirm our research paradigm based on the theoretical model of overloading of conflict, and stress the role of the individual level of intolerance of incongruity in the dynamics of aesthetic preferences. This survey also allows to obtain an effect of 
generalization of the theoretical model through the empirical verification with different types of images.

\title{
Keywords
}

\author{
Aesthetic Preferences, Incongruity Intolerance, Mental Schemata, Personality, Perception
}

\section{Introduction and Previous Studies}

As reported in the past by Bonaiuto, Biasi, Giannini, \& Chiodetti (2001), the importance and utility of studying the world of illustrations and messages is widely recognized in general and dynamic psychology. Nevertheless, the relevance of this field is also acknowledged in aesthetics, the psychology of design and personality psychology. For a consistent and articulated series of pertinent past contributions, we can mention studies and reviews by Anastasi (1964), Bonaiuto (1983, 2006), Cupchik, Leonard, \& Lirvine-Kopetski (1998), Schumann \& Thorson (1999), and several others.

The new investigation described in these pages aims to contribute to demonstrate that:

a) It is possible to find interesting relations between human motivations and cognitive processes by carefully analyzing advertising illustrations which offer products in order to satisfy one or more human motivations.

b) Aesthetic preferences for different illustration categories are determined by constellations of dominant motivations detected according to precise personality indicators, and connected to different, even opposite, fundamental cognitive processes (see also Biasi, Bonaiuto, Giannini, \& Chiappero, 1999).

Let us firstly define and describe a pair of what we consider fundamental cognitive processes. These are the opposing “completion” and "contradiction” processes.

The completion process consists of the beholder actively producing perceptual parts that are not concretely given in order to make objects, events, people and environments appear complete. These parts are intuitively or directly grasped at the perceptual reality level when viewers examine configurations that give sufficient cues and that, without this active process, would otherwise appear disturbingly incomplete (Michotte, Thinés, \& Crabbé, 1967; Metzger, 1953; Kanizsa, 1979).

Because these kinds of inference are constructed by applying preexisting mental schemata, it is also true that the completion process confirms these mental schemata. This process uses corresponding schemata, but does not leave them unchanged: rather it reinforces their existence and functioning (Bonaiuto, 1983; Biasi, ChiappettaCajola, \& Bonaiuto, 2010).

Furthermore, the completion leads to satisfaction of congruence and regularity needs, on which the drives for making sure predictions are partially based, by finding consistent explanations, avoiding inadequacy, gaps or fractures in self-image and in the image of others and of the environment.

The contradiction process consists of establishing a more or less vivid open psychological conflict that arises when perception data are connected to the observer's preexisting mental schemata and demands. These are, however, relatively incompatible with the images, which take on a dissonant, incongruent type of nature (Bruner \& Postman, 1949; Berlyne, 1960; Cowan, 1977; Bonaiuto, Massironi, \& Bartoli, 1975; Biasi, Bonaiuto, \& Levin, 2015).

Terms such as paradoxes, oddities and bizarreries are used to refer to this process. In these cases, mental schemata are more or less challenged. They are simultaneously enhanced, revealed and oriented to modification. As a result, the correlated expectations are no longer safe.

The cognitive process of contradiction may lead to satisfaction of psychological conflict needs, corresponding to a constellation of drives, opposite to those consonant with the completion process.

As regards this type of relations, previous investigations by Bonaiuto (1983) indicated that advertising illustrations based on a specific group of human motivations such as nutrition, sexuality, sociality, ordered knowledge and achievement through conformity to social norms, are generally made by illustrators in an intuitive but nevertheless efficacious way, proposing the visual process of amodal completion. On the other hand, advertising illustrations based on a different group of human demands, that are curiosity, aggression, the need for adventure and achievement through independence, are often made by contradicting shared mental schemata, proposing 
conflictual situations and mainly visual incongruities.

This non-random correspondence is quite reasonable if we consider the structure of the goal-objects of human motivations. By carrying out appropriate phenomenological analyses and psychodynamic reflections, several of the customer goal-objects may be placed within the two categories of completion and open conflict (contradiction). The self is perceived as incomplete when experiencing hunger, sexual desire, social need and the need to consolidate and enhance one's identity; and achieving the respective goal-objects each time allows the appropriate completion. The perceived open conflict in turn reproduces the structure of great contrapositions between elements of reality that may involve the self, as when activating exploratory needs, emotional tension needs, destructive needs, or self-assertion through independence and obstacle abatement. Isomorphism between the goal-objects of the customer (that is a large and vital completion of the self, or an open conflict, respectively), and cognitive processes proposed to him by each illustration, should be considered a key-condition and a main psychological mechanism by which differences in frequency distributions of customer preferences for specific and corresponding advertising illustrations are determined.

Apart from applications in persuasion processes, our main interest in drafting this work focuses on the implications concerning aesthetic emotion and personality psychology.

In this sense, we feel it appropriate to also use a recent and very quick personological evaluation procedure, which allows distinguishing between very incongruity intolerant and very incongruity tolerant adults: the Building Inclination Test (BIT). This test was designed and used in experiments by Bonaiuto, Giannini, \& Bonaiuto (1989), and has been the subject of later methodological and application contributions (Bonaiuto, Giannini, Biasi, \& Bartoli, 1996). The individual index of incongruity intolerance obtained with this instrument has been shown to significantly correlate negatively with ambiguity tolerance-a trait measured with the MTA-50, a scale designed by Norton (1975) — and to positively correlate with behavioural rigidity, measured with the Zazzo \& Stamback (1964) inventory.

The use of the BIT is described further on in the section dealing with the study method. We may just recall here that it is a test based on non-verbal incongruity, unlike the others based on questionnaires used in organisational and work psychology (Driver, Brousseau, \& Hunsaker, 1990; Hunsaker, 1975; Hunsaker \& Landkamer, 1995).

The incongruity intolerance trait, measured using the BIT, has been seen over the various studies to be responsible for the aesthetic devaluation of art works that show the observer perceptually conflicting configurations, that are thus incongruent with respect to the beholder's mental schemata and demands. These same art works are instead positively appreciated by subjects that have the opposite traits, i.e. those who are very incongruity tolerant (Bonaiuto, Giannini, \& Biasi, 2002).

The existence of individual differences shoudbe included in the domain of experimental phenomenology because the study of several phenomena in perception as well in other processes reveals that intensity and direction phenomena and of the corresponding psychological processes is not the same for every person. One of the first experimental phenomenologists, that is Benussi (1904), studying and measuring visual illusion, was able to detect the existence of consistent individual differences and outlined the two opposite categories named Global versus Analytical subjects. This distinction was then highly developed by Wellek (1961) and Witkin, Faterson, Goodenough, \& Karp (1962) and others. Other vivid individual differences in cognitive styles are shown if we focus the perception of incongrous configurations. In this sense, the Building Inclination Test (BIT) represents a very quick evaluation procedure, which allows distinguishing between very incongruity intolerant and very incongruity tolerant adults.

In the previous study, Bonaiuto, Biasi, Giannini, \& Chiodetti (2001) showed that these traits give rise to opposing aesthetic appraisals even when we are dealing with the aesthetic appreciation of advertising illustrations.

We present here a development of this study applying the above mentioned research paradigm to classical and modern pictorial images, as detailed in next paragraphs.

\section{An Empirical Research Conducted with Classical and Modern Artistic Paintings}

\subsection{Hypothesis and Methodology}

We apply the research paradigm presented above to classical and modern pictorial images: 6 paintings based on completion phenomena, 6 paintings based on incongruity phenomena and 6 mixed paintings.

We hypothesize that this three categories of images-that give the beholder pressing confirmation or contra- 
diction processes of expectations and mental schemata—will be in strict consonance with opposite constellations of motivational systems and are related to personality trait.

In particular, we expect that very incongruity intolerant participants will aesthetically appreciate the completion pictures, but they do not like them incongruent pictures. The very incongruity tolerant participants would be able to appreciate the three types of images presented including the incongruent ones. The third group of participants characterized by intermediate level of incongruity intolerance, would obtain intermediate scores.

\subsection{Participants}

The template is used to format your paper and style the text. All margins, column widths, line spaces, and text fonts are prescribed; please do not alter them. You may note peculiarities. For example, the head margin in this template measures proportionately more than is customary. This measurement and others are deliberate, using specifications that anticipate your paper as one part of the entire journals, and not as an independent document. Please do not revise any of the current designations.

\subsection{Materials, Instruments and Procedure}

\subsubsection{Illustrations and Evaluation Scales}

Three types of classical and modern paintings were proposed for testing, reproduced on A4 paper sheets: six show the predominant completion phenomena, other six are based on clear incongruous situations and the last six show completion phenomena mixed with incongruity (see Tables 1-3).

The first kind of images encourage the observer to implement above all an intense completion process, while, the opposite kind of images give the observer a conspicuous contradiction of commonly shared mental schemata. The mixed images includes the two different phenomena at intermediate level.

Each illustration is listed with the type of product advertised and its mark, together with the specific source the illustration has been taken from. A short printed report was also prepared with bipolar evaluation scales, having eleven points between pairs of opposite adjectives or sentences. Among these scales, one is particularly directly related to aesthetic appreciation or repulsion, being arranged between the adjectives "beautiful" and "ugly".

Table 1. List of paintings based on completion phenomena: Expectation confirmation.

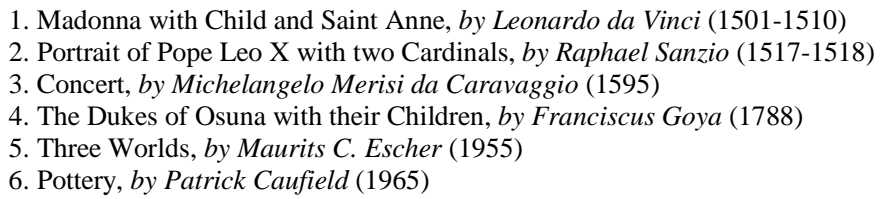

Table 2. List of paintings based on incongruity phenomena: Expectation contradiction.

\footnotetext{
1. David and Goliath, by Michelangelo Merisi da Caravaggio (1597-1598)

2. Flight of Wizards, by Franciscus Goya (1797-1798)

3. Presage of Civil War. Soft construction with boiled beans, by Salvador Dalì (1936)

4. L'Ange du Foyer ou le Triomphe du Surréalisme, by Max Ernst (1937)

5. Portrait of Marie Thérèse Walter, by Pablo Picasso (1939)

6. House of Stairs, by Maurits C. Escher (1951)
}

Table 3. List of paintings based on completion mixed with incongruity.

\footnotetext{
1. Carrying the Dead Christ, by Raphael Sanzio (1507)

2. The Librarian, by Giuseppe Arcimboldo (ca.1566)

3. Judith and Holofernes, by Michelangelo Merisi da Caravaggio (1599)

4. Abraham stopped by the Angel from sacrificing his son Isaac,

by Rembrandt van Run (1635)

5. Shootings of the 3rd of May 1808, by Franciscus Goya (1814)

6. Another Word, by Maurits C. Escher (1947)
} 
Other scales are related to the evaluation of parallel physiognomic and structural properties, and two scales to the attributed efficacy and persuasive power of each illustration shown.

\subsubsection{The Building Inclination Test (BIT)}

We will briefly describe the test: the assessment setting includes a tridimensional model of a modern tower building, $40 \mathrm{~cm}$. tall, tilted 7 degrees from the vertical, painted in realistic colors, and having several other realistic details. The model is shown standing on a table and may be rotated on a circular base. It is well-lit without shadows and is against a neutral background.

It is shown in four fundamental orientations with respect to the observer: leaning forward, leaning backward, leaning to the right and to the left. A comparison scale for evaluating the apparent lean, according to the method of limits, is also present in the same visual field. It shows 7 elements (each $4.8 \mathrm{~cm}$. high), outlined with black contours on white cardboard, and leaning from the vertical with a progressive increase from 1 to 13 degrees. The subject also uses a second comparison scale in which the elements lean the same degrees in the opposite direction, to produce half of the total number of judgments.

The experimenter first regulates the orientation of the model, keeping it out of sight until ready. Then, four basic orientations are shown in random succession, each of them three times with the first comparison scale whose elements are leaning to the right (as in the figure), and three times with the second comparison scale, whose elements are leaning to the left. In this way, a total of 24 presentations are made. Each subject, individually examined, is asked to look freely every time and to choose, from the underlying comparison scale, the type of inclination perceptually most similar to the building appearance.

The images offered by the building model when it leans forward or backward are highly ambiguous, because it is hard to determine perceptually whether and to what extent it is really leaning. Under such ambiguous perceptual conditions, the very incongruity intolerant subjects show high perceptual defence against the architectural anomaly, with strong underestimation, ranging from 0 to 3 degrees of inclination, instead of 7 which is the realistic choice. On the other hand, the very incongruity tolerant subjects, that is, persons who appreciate anomalies, show perceptual facilitation and emphasis. They evaluate the building as leaning 6 degrees or more.

The individual score for incongruity (i.e. conflict) intolerance is obtained by first calculating the mean value of the evaluations of the anomaly, expressed in degrees, in the ambiguous observation condition. This value is then subtracted from a ceiling value of 14 degrees, which represents a maximum measurement, double the real inclination of the model and therefore higher than the top value of the comparison scales (so that it is never reached in the individual mean values).

Hence, the formula is as follows: $\mathrm{I}=14-\mathrm{A}$, where $\mathrm{I}=$ Incongruity Intolerance (to be determined) and A = average evaluation of the model, expressed in degrees, in the Ambiguous observation conditions. The resulting score appears to be proportional to the intensity of the defense against incongruity and may therefore constitute a suitable index for incongruity intolerance.

The experience gained in previous studies suggests selecting as very incongruity intolerant people those who score 11 points or above. The group of very incongruity tolerant subjects can include those who score 8.30 points or less.

\subsubsection{Procedure}

We selected, from the larger samples, 18 colour laser reproductions of classical and modern paintings on A4 paper sheets. Six show the predominant completion phenomena, other six are based on clear incongruous situations and the last six show completion phenomena mixed with incongruity.

Each illustration was shown randomly on a lectern, one at a time, in order to be individually evaluated. As already mentioned above, 20 incongruity very intolerant persons plus 20 incongruity very tolerant ones (both genders equally distributed) and 20 intermediate participants were selected using the above-mentioned tool, the Building Inclination Test, and assessing the incongruity intolerance index with its relatively quick procedure.

The 60 selected participants assigned the aesthetic scores and the other relevant quality scores to each illustration, using the 11-point bipolar evaluation scales whose positions and directions were systematically rotated. Double-blind methodological conditions were also assured.

\subsection{Results}

We computed data from the bipolar evaluation scales whose adjectives appear specifically related to aesthetic 
experience: Beautiful/Ugly.

The results clearly confirmed the hypotheses (Figure 1) and show that very incongruity intolerant participants highly aesthetically appreciate the completion pictures, but they do not like them incongruent pictures. Otherwise the very incongruity tolerant participants are able to appreciate all three types of images presented, and attribute a positive aesthetic scores also to the incongruent, conflictual pictures. The third group of participants characterized by intermediate level of incongruity intolerance, obtain intermediate scores.

Great similarities can be seen between the results obtained in this study with images of artistic paintings and the preliminary one conducted by Bonaiuto, Biasi, Giannini, \& Chiodetti (2001) with advertising illustrations based on completion versus contradiction phenomena: the two opposite categories of illustrations appear always remarkably different from each other and that they often appear with different physiognomic properties to the two contrasting personality categories.

In this preliminary demonstration the differences in evaluations are systematic and particularly noticeable when we examine scores assigned to incongruous advertising illustrations. Two opposing semantic profiles are obtained: one, which corresponds to evaluations made by the very tolerant subjects, is optimistic and emotionally positive; the other, corresponding to the evaluations made by the very intolerant subjects, is on the whole rather neutral. Means, standard deviations and statistical significance data are shown in Table 4 and Table 5 .

Differently from the first study in our new survey we added a third group of participants that have intermediate levels of incongruity intolerance and a third group of images called mixed and, as we expected, we obtained intermediate results on aesthetic appreciation's scores. As reported before, now we choose to compute in particular data from the bipolar evaluation scale mainly related to aesthetic experience (Beautiful/Ugly).

\section{Discussion and Conclusions}

Considering the theoretical model of overloading of psychological conflict, the high individual level of incongruity intolerance is related to an increase of negative emotions, aggressive motivation and cognitive consequences as mental rigidity (Biasi, Bonaiuto, \& Levin, 2015).

Within certain limits, in order to avoid and/or reduce the unpleasant features of such an affective activation, the high intolerant participant may reject other kinds of psychological conflict, among which there are cognitive incongruities such as those well represented in the incongruent classical or modern pictures here presented.

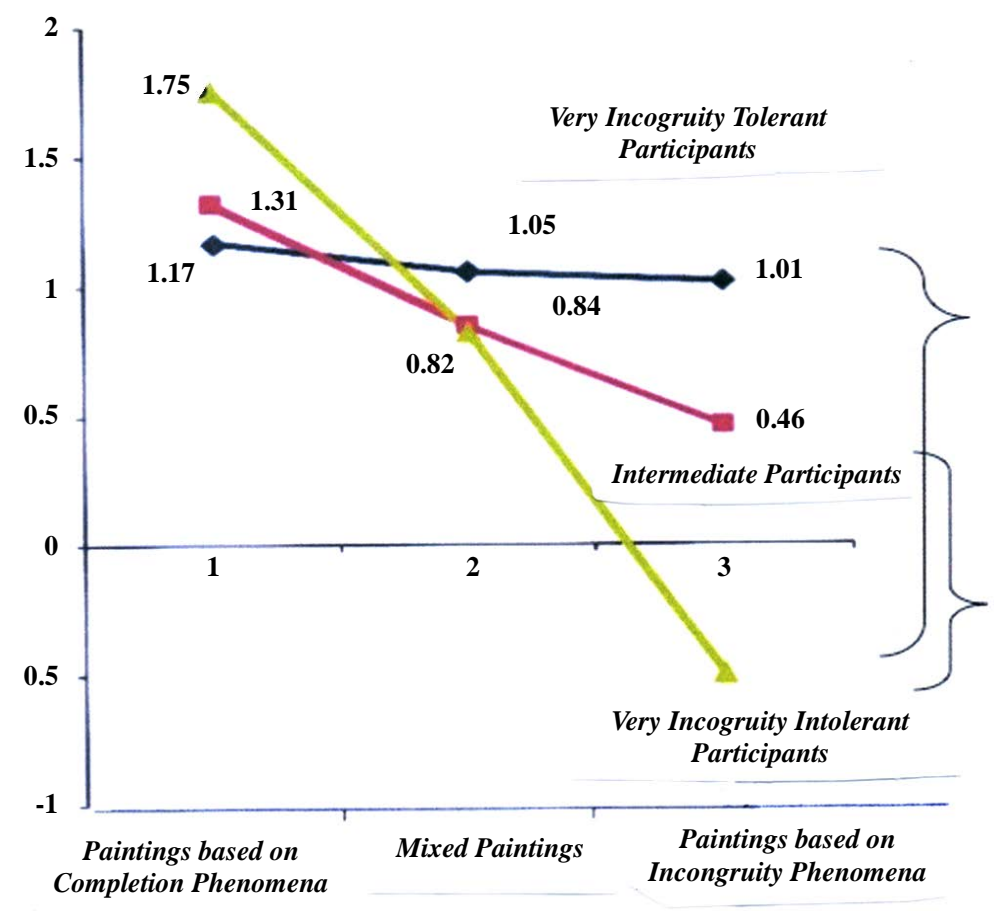

Figure 1. Mean scores related to aesthetic experience: Beautiful (+)/Ugly (-). 
Table 4. Means, standard deviations (in Brackets) and statistical significance concerning evaluations given by very incongruity tolerant subjects through 11-point bipolar scales, applied to completion and to contradiction advertising illustrations (Bonaiuto, Biasi, Giannini, \& Chiodetti, 2001).

\begin{tabular}{lccc}
\hline \multicolumn{1}{|c}{ 11-Point Bipolar Evaluation Scales } & $\begin{array}{c}\text { Completion Advertising } \\
\text { Illustration }(n=16)\end{array}$ & $\begin{array}{c}\text { Contradiction Advertising } \\
\text { Illustration }(n=16)\end{array}$ & $\begin{array}{c}\text { Statistical Analyses } \\
\text { (Student's t test })\end{array}$ \\
\hline Beautiful (+)/Ugly (-) & $+0.80(1.25)$ & $+1.31(1.31)$ & $\mathrm{t} 38=1.27$ n.s. \\
Attractive (+)/Repulsive (-) & $+0.53(1.18)$ & $+1.46(1.43)$ & $\mathrm{t} 38=-2.26 p<0.02$ \\
Pleasant (+)/Unpleasant (-) & $+0.76(1.28)$ & $+1.40(1.33)$ & $\mathrm{t} 38=1.53 p<0.07$ \\
Cheerful (+)/Sad (-) & $+0.49(0.75)$ & $+1.27(0.75)$ & $\mathrm{t} 38=3.31 p<0.01$ \\
Restful (+)/Anxiety-Inducing (-) & $+0.97(1.01)$ & $+1.11(0.99)$ & $\mathrm{t} 38=0.44$ n.s. \\
Relaxing (+)/Stressing (-) & $+1.02(1.01)$ & $+0.87(1.31)$ & $\mathrm{t} 38=0.43$ n.s. \\
Harmonious (+)/Conflictual $(-)$ & $+1.13(0.94)$ & $+1.56(0.92)$ & $\mathrm{t} 38=0.73$ n.s. \\
Funny $(+) /$ Serious $(-)$ & $-0.85(0.86)$ & $+1.59(1.16)$ & $\mathrm{t} 38=8.57 p<0.001$ \\
Effective (+)/Uneffective $(-)$ & $+1.01(1.30)$ & $+1.42(1.11)$ & $\mathrm{t} 38=1.50 p<0.08$ \\
Convincing (+)/Unconvincing $(-)$ & $+0.86(0.97)$ & $\mathrm{t} 38=1.71 p<0.05$ \\
\hline
\end{tabular}

Table 5. Means, standard deviations (in brackets) and statistical significance concerning evaluations given by very incongruity intolerant subjects through 11-point bipolar scales, applied to completion and to contradiction advertising illustrations (Bonaiuto, Biasi, Giannini, \& Chiodetti, 2001).

\begin{tabular}{lccc}
\hline \multicolumn{1}{c}{ 11-Point Bipolar Evaluation Scales } & $\begin{array}{c}\text { Completion Advertising } \\
\text { Illustration }(n=16)\end{array}$ & $\begin{array}{c}\text { Contradiction Advertising } \\
\text { Illustration }(n=16)\end{array}$ & $\begin{array}{c}\text { Statistical Analyses } \\
\text { (Student’s } t \text { test })\end{array}$ \\
\hline Beautiful (+)/Ugly (-) & $+1.31(1.26)$ & $+0.30(0.97)$ & $\mathrm{t} 38=2.84 p<0.01$ \\
Attractive (+)/Repulsive (-) & $+1.53(1.23)$ & $+0.27(0.99)$ & $\mathrm{t} 38=3.58 p<0.001$ \\
Pleasant (+)/Unpleasant (-) & $+1.42(1.27)$ & $+0.14(0.99)$ & $\mathrm{t} 38=3.55 p<0.001$ \\
Cheerful (+)/Sad (-) & $+0.80(1.00)$ & $-0.02(1.10)$ & $\mathrm{t} 38=2.47 p<0.01$ \\
Restful (+)/Anxiety-Inducing (-) & $+1.34(1.19)$ & $-0.12(1.04)$ & $\mathrm{t} 38=4.16 p<0.001$ \\
Relaxing (+)/Stressing (-) & $+1.24(1.15)$ & $-0.03(1.01)$ & $\mathrm{t} 38=3.71 p<0.001$ \\
Harmonious (+)/Conflictual (-) & $+1.56(1.13)$ & $-0.15(1.00)$ & $\mathrm{t} 38=5.07 p<0.001$ \\
Funny (+)/Serious (-) & $-1.08(1.29)$ & $+1.49(1.31)$ & $\mathrm{t} 38=6.14 p<0.001$ \\
Effective (+)/Uneffective (-) & $+1.57(1.23)$ & $+0.79(1.06)$ & $\mathrm{t} 38=1.57 p<0.02$ \\
Convincing (+)/Unconvincing $(-)$ & $+1.16(1.51)$ & $-0.38(1.25)$ & $\mathrm{t} 38=1.77 p<0.05$ \\
\hline
\end{tabular}

In conclusion, the incongruity very intolerant subjects give their aesthetic preference to situations confirming their mental schemata and expectations and tend to refuse conflictual situations, oddities and paradoxes in advertising as well as artistic paintings.

On the contrary, we may conclude that the very tolerant participants are characterized by a low level of psychological conflict and anxiety, and so they appear inclined to appreciate also advertising messages or artistic pictures rich in conflictual elements and incongruity aspects.

We consider that these participants are not anxious and worried in case of disconfimation of their pre-existing mental schemata and presumably they satisfy a specific curiosity and motivation to the adventure.

This kind of personality considerably less appreciate the reassuring images based on completion effect, that confirm pre-existing mental schemata and correspond to reassuring motivations.

In summary, collected data confirm our research paradigm based on the theoretical model of overloading of psychological conflict, and stress the role of the individual level of intolerance of incongruity in the dynamics of 
aesthetic preferences. This survey also allows obtaining an effect of generalization of the theoretical model through the empirical verification with different types of images.

\section{References}

Anastasi, A. (1964). Fields of Applied Psychology. New York: McGraw Hill.

Benussi, V. (1904). Zur Psychologie des Gestalterfassens. In A. Meinong, Hrsg., Untersuchungen zur Gegenstandstheorie und Psychologie (pp. 303-448). Leipzig: Barth.

Berlyne, D. E. (1960). Conflict, Arousal and Curiosity. New York: McGraw Hill. http://dx.doi.org/10.1037/11164-000

Biasi, V., Bonaiuto, P., \& Levin, J. (2015). Relation between Stress Conditions, Uncertainty and Incongruity Intolerance, Rigidity and Mental Health: Experimental Demonstrations. Health, 7, 71-84. http://dx.doi.org/10.4236/health.2015.71009

Biasi, V., Bonaiuto, P., Giannini, A. M., \& Chiappero, E. (1999). Personological Studies on Dancers: Motivations, Conflicts and Defense Mechanisms. Empirical Studies of the Arts, 17, 171-186. http://dx.doi.org/10.2190/B2VW-BG5Q-2T9C-HNDB

Biasi, V., Chiappetta Cajola, L., \& Bonaiuto, P. (2010). Valutare la formazione degli schemi mentali nei disturbi dell'apprendimento (Evaluating the Formation of Mental Schemata in Learning Disorders). Journal of Educational, Cultural and Psychological Studies, 2, 117-138.

Bonaiuto, P. (1983). Processicognitivi e significatinelleartivisive. Paper Presented at the Meeting "Linguaggivisivi, Storiadell’Arte, Psicologiadellapercezione”, Rome. In L. Cassanelli (Ed.), Linguaggivisivi, Storiadell'Arte, Psicologiadellapercezione (pp. 47-79). Rome: Multigrafica.

Bonaiuto, P. (2006). Art, Science, and Humor: The Study of Humorous Experience at the Intersection between Psychology and the Art World. Empirical Studies of the Arts, 24, 3-41. http://dx.doi.org/10.2190/47F3-NKJ0-ER8L-KKVH

Bonaiuto, P., Biasi, V., Giannini, A. M., \& Chiodetti, M. (2001). Motivational Appeal, Aesthetic Appreciation and Attributed Efficacy of Advertising Illustrations. Empirical Studies of the Arts, 19, 287-296.

Bonaiuto, P., Giannini, A. M., \& Biasi, V. (2002). Immagini conflittuali vs. armoniche, intolleranza dell'incongruità e preferenze estetiche negli adulti. In R. Tomassoni (a cura di), Psicologiadelle Artioggi. Milano: Angeli.

Bonaiuto, P., Giannini, A. M., \& Bonaiuto, M. (1989). Maximizers, Minimizers, Acceptors, Removers and Normals: Diagnostic Tools and Procedures. Rassegna di Psicologia, 6, 80-87.

Bonaiuto, P., Giannini, A. M., Biasi, V., \& Bartoli, G. (1996). Stilicognitivi, intolleranzadell’incongruità e atteggiamenti verso le trasgressioni di regole sportive. In G. V. Caprara, \& G. P. Lombardo (Eds.), Temi di Psicologia e Sport (pp. 57-93). Rome: C. O. N. I., \& Universitàdegli Studi di Roma “La Sapienza”.

Bonaiuto, P., Massironi, M., \& Bartoli, G. (1975). Atteggiamenti verso schemi di riferimento, utilizzazione di modelli, esigenze di libertàdella persona. Quadrangolo. Rivista di psicoanalisi e scienzesociali, 2, 100-110.

Bruner, J. S., \& Postman, L. (1949). On the Perception of Incongruity: A Paradigm. Journal of Personality, 18, $206-223$. http://dx.doi.org/10.1111/j.1467-6494.1949.tb01241.x

Cowan, T. M. (1977). Organizing the Properties of Impossible Figures. Perception, 6, 41-56. http://dx.doi.org/10.1068/p060041

Cupchik, G. C., Leonard, G., \& Irvine-Kopetski, D. (1998). Advertisements: Multileveled in Word and Image and in the Mind of the Beholder. Empirical Studies of the Arts, 16, 115-135. http://dx.doi.org/10.2190/LDAA-EN1N-GDJ6-CEPF

Driver, M. J., Brousseau, K. R., \& Hunsaker, P. L. (1990). The Dynamic Decision Maker. New York: Harper \& Row.

Hunsaker, P. L. (1975). Incongruity Adaptation Capability and Risk Preference in Turbulent Decision-Making Environments. Organizational Behavior and Human Decision Processes, 14, 173-185. http://dx.doi.org/10.1016/0030-5073(75)90022-7

Hunsaker, P. L., \& Landkamer, M. J. (1995). Decision Style, Incongruity Preference and Leadership Style. Psychological Reports, 76, 284-286. http://dx.doi.org/10.2466/pr0.1995.76.1.284

Kanizsa, G. (1979). Organization in Vision: Essays on Gestalt Perception. New York: Praeger.

Metzger, W. (1953, 1975). Gesetze des Sehens. Frankfurt a. M.: Kramer.

Michotte, A., Thinés, G., \& Crabbé, G. (1967). Les complements amodaux des structures perceptives. Louvain: Publications Universitaires de Louvain.

Norton, R. W. (1975). Measurement of Ambiguity Tolerance. Journal of Personality Assessment, 39, 607-619. http://dx.doi.org/10.1207/s15327752jpa3906_11

Schumann, D. W., \& Thorson, E. (Eds.) (1999). Advertising and Consumer Psychology. Mahwah, NJ: Erlbaum.

Wellek, A. (1961). The Contribution of the Perception-Typological Approaches to the Typology of Character, and the Role 
of Sensation, Imagination, and Thinking in the Organizational Concept of Personality. Acta Psychologica, 19, 1-8. http://dx.doi.org/10.1016/s0001-6918(61)80321-1

Witkin, H. A., Dyk, R. B., Faterson, H. F., Goodenough, D. R., \& Karp, S. A. (1962). Psychological Differentiation. New York: Wiley and Sons.

Zazzo, R., \& Stamback, M. (1964). Un test de pérséveration. In R. Zazzo, N. Galifret-Granjon, T. Mathon, H. Santucci, \& M. Stamback (Eds.), Manuel pour l'examenpsychologique de l'enfant (Vol. 8). Neuchatel: Delachauxet Niestlé. 